\title{
review
}

\section{Cisplatin and beyond: molecular mechanisms of action and drug resistance development in cancer chemotherapy}

\author{
Tomaz Makovec \\ Institute of Biochemistry, Faculty of Medicine, University of Ljubljana, Ljubljana, Slovenia \\ Radiol Oncol 2019; 53(2): 148-158. \\ Received 20 July 2018 \\ Accepted 5 September 2018 \\ Correspondence to: Tomaž Makovec, Ph.D., Institute of Biochemistry, Faculty of Medicine, University of Ljubljana, Vrazov trg 2, \\ SI-1000 Ljubljana, Slovenia. Phone: +386 (0)1 543 640; Fax: +386 (0)1 5437 641; E-mail: tomaz.makovec@mf.uni-lj.si \\ Disclosure: No potential conflicts of interest were disclosed.
}

Background. Platinum-based anticancer drugs are widely used in the chemotherapy of human neoplasms. The major obstacle for the clinical use of this class of drugs is the development of resistance and toxicity. It is therefore very important to understand the chemical properties, transport and metabolic pathways and mechanism of actions of these compounds. There is a large body of evidence that therapeutic and toxic effects of platinum drugs on cells are not only a consequence of covalent adducts formation between platinum complexes and DNA but also with RNA and many proteins. These processes determine molecular mechanisms that underlie resistance to platinum drugs as well as their toxicity. Increased expression levels of various transporters and increased repair of platinum-DNA adducts are both considered as the most significant processes in the development of drug resistance. Functional genomics has an increasing role in predicting patients' responses to platinum drugs. Genetic polymorphisms affecting these processes may play an important role and constitute the basis for individualized approach to cancer therapy. Similar processes may also influence therapeutic potential of nonplatinum metal compounds with anticancer activity.

Conclusions. Cisplatin is the most frequently used platinum based chemotherapeutic agent that is clinically proven to combat different types of cancers and sarcomas.

Key words: cisplatin; molecular mechanisms; chemotherapy; resistance

\section{Introduction}

Drug resistance is a wide spread and well known phenomenon among anticancer medications and platinum drugs are not exceptions. The use of these drugs in chemotherapy is hampered by extrinsic and intrinsic resistance of cells. Although many cancer cells are initially susceptible to chemotherapy with platinum drugs, over time they may develop resistance through more efficient DNA damage repair, drug inactivation with glutathione and metallothioneins and drug efflux with various transport systems located in cell membrane. In this review the chemical properties, metabolism and transport of platinum and similar compounds and how they are implicated in the developing in cell resistance and toxicity are described. The knowl- edge of mechanism of action of these drugs reveals mechanisms of resistance and toxicity. The aim of this review is also to provide recent data concerning hypersensitivity reactions to platinum-containing chemotherapy agents. To minimize toxicity, resistance and hypersensitivity reactions to platinum drugs the new metallodrugs were developed. A brief summary of these agents is also presented.

\section{The discovery of platinum compounds as anticancer agents}

Until the mid-1960s, cancer chemotherapy was based on purely organic compounds. An accidental discovery of anticancer properties of inorganic co- 
ordination compounds based on platinum opened the door also for inorganic compounds. In 1965, Barnett Rosenberg discovered that platinum complex generated during electrolysis from platinum electrodes inhibited binary fission in the Escherichia coli bacteria. His group investigated the influence of alternating currents of different frequencies on the ability of the cells to divide. To their surprise, they found that certain frequencies of a current reduced the number of cells growing in the media to a large extent. They also discovered that bacteria were transformed into long rods which indicated that the cells were growing but not dividing. With a number of control experiments, they showed that while electric current itself has no influence on cell division, the current was causing a small amount of metal on the surface of the platinum electrodes to dissolve as a complex; these chemical substances, apart from the electric current, were affecting the growth of E. coli. Suspecting $\mathrm{Pt}^{4+}$, which elemental platinum in the electrode was being oxidized into, they first tested a sample of $\left(\mathrm{NH}_{4}\right)_{2} \mathrm{PtCl}_{6}$ and found no effect on the growth of the bacteria. However, if the solution of $\left(\mathrm{NH}_{4}\right)_{2} \mathrm{PtCl}_{6}$ was irradiated by a light source, the resulting solution became very effective in inhibiting the division of $E$. coli. They found that $\mathrm{Pt}^{2+}$ species were produced in photoreactions and subsequently they tested many platinum complexes, the six coordinate octahedral cis- $\left[\mathrm{PtCl}_{4}\left(\mathrm{NH}_{3}\right)_{2}\right]$, with $\mathrm{Pt}^{4+}$ ion and cis-[ $\left.\mathrm{PtCl}_{2}\left(\mathrm{NH}_{3}\right)_{2}\right]$, with $\mathrm{Pt}^{2+}$ ion that were effective in arresting the cell division. ${ }^{1}$

Rosenberg and his group concluded that compounds capable of inhibiting $E$. Coli division could also be useful for treating cancer. They found that planar complex which contained $\mathrm{Pt}^{2+}$ ion with cis configuration - later known as cisplatin - was very effective at arresting sarcoma 180 and leukaemia L1210 cells while trans isomer exhibited little antitumor activity. ${ }^{1}$ This observation also led to the discovery of the effectiveness of this compound at regressing the mass of sarcomas in rats. ${ }^{2}$

Turning these findings into a useful commercial product was a hard task at that time. When Rosenberg carried out his investigations, all anticancer drugs approved for use in the United States were organic compounds, either natural or synthetic. Anything which contained heavy metal (platinum is the second neighbour of mercury) was treated as a toxic compound that should be kept away from humans. For this reason, Rosenberg convinced the National Cancer Institute that they carried out more extensive animal tests on the platinum complexes. The compound was very effective in those human cancers where other forms of chemotherapy resulted in no improvements and in 1979 he patented his new discovery - the use of cisplatin. He couldn't patent the compound since it had been synthesized 100 years earlier by Peyrone. ${ }^{3}$ Later in 1979, the Bristol-Myers (now Bristol-Myers Squibb), who intensively researched anticancer drugs, carried out additional investigations to provide information about the safety and the efficacy for the Food and Drug Administration (FDA). In 1978, the FDA approved cisplatin for use in cancer chemotherapy. Suddenly, it was appropriate for inorganic chemists to send their compounds to Cancer Institutes for screening for antitumor activities. ${ }^{4}$ This resulted in a number of new platinum and non-platinum based compounds that showed promise to become successful anticancer compounds. Since its discovery, five other platin drugs have received approval in various countries: besides carboplatin and oxaliplatin there are another three gaining approval in single markets; nedaplatin in Japan, lobaplatin in China and heptaplatin in Korea. ${ }^{5}$

\section{Chemistry of cisplatin}

The behaviour of cisplatin in aqueous solution is presented in Figure 1.

The chemistry of cisplatin is completely different from all other chemistries of typical organic anticancer drugs. In blood, the concentration of

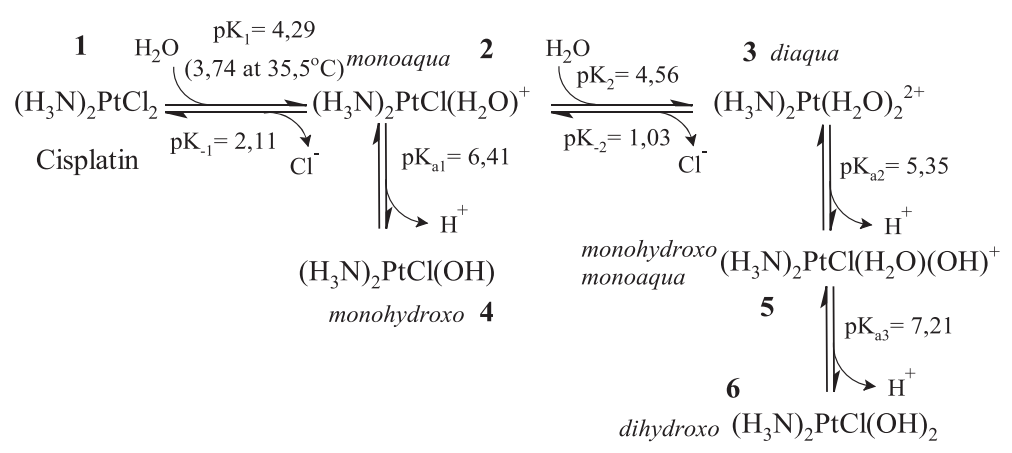

FIGURE 1. The behaviour of cisplatin in aqueous solution. Cisplatin (1) is a brightyellow solid; when dissolved in water it is attacked by water molecules and as a result one of the chloride ions is eliminated and monoaqua (2) species is formed. Diaqua species (3) is formed when the second water molecule replaces the chloride ion. Water replaces chloride ions because the metal and nitrogen form stronger bond than metal and the chloride ion. Bound water became very acidic and at physiologic $\mathrm{pH}$ became completely deprotonated - as a monohydroxo form (4), and the product of the dissociation of the second proton from the diaqua form is dihydroxo species (6). Logarithms of rate constants $\left(\mathrm{pK}_{1}, \mathrm{pK}_{-1}, \mathrm{pK}_{2}\right.$ and $\left.\mathrm{pK}_{-2}\right)$ are given for $25^{\circ} \mathrm{C}$ and of dissociation constants $\left(\mathrm{pK}_{\mathrm{a} 1}, \mathrm{pK}_{\mathrm{a} 2}\right.$ and $\left.\mathrm{pK} \mathrm{a}_{3}\right)$ for $27^{\circ} \mathrm{C}$. 
the chloride ion is about $105 \mathrm{mM}$ and, according to Le Chatelier's principle, the loss of the chloride ion from cisplatin is suppressed by the chloride ion in solution; the reaction shown in Figure 1 does not progress very far to the right (from 1 to 2). According to the first order kinetics for conversion from 1 to 2, the half-life for cisplatin at $35.5^{\circ} \mathrm{C}$ is $1.05 \mathrm{~h}$. The binding of a water molecule to the $\mathrm{Pt}^{2+}$ ion makes water very acidic and monoaqua species 3 is dissociated in the monohydroxo complex 4. So in an aqueous solution with the high chloride concentration the forms $\mathbf{1}, 2$ and $\mathbf{4}$ predominate. In the cytoplasm, where chloride ion concentration is only $4 \mathrm{mM}$, the equilibria is shifted to the right and forms 3,5 and 6 predominate. A common route of cisplatin administration is the infusion of the solutions such as Platino ${ }^{\circledR}$ and Plationol ${ }^{\circledR} \mathrm{AQ}$, which contain $3.3 \mathrm{mM}$ cisplatin $(1 \mathrm{mg} / \mathrm{ml})$ and $154 \mathrm{mM}$ sodium chloride, $\mathrm{NaCl}$ (normal saline solution). Since the $\mathrm{pH}$ is adjusted to $\mathrm{pH}$ about 4 solution in Platinol contains mainly (95\%) of species $\mathbf{1}$ and only smaller amounts of $\mathbf{3}$ and $\mathbf{4}$.

\section{Uptake and removal of cisplatin from cells}

\section{Cisplatin in blood}

Since the concentration of chloride in blood is lower than in the infusion solution (105 versus 154 $\mathrm{mM}$ ), the equilibria (Figure 1) is shifted to the right. Because the carbonate and phosphate ions react with aquated cisplatin forms and because some platinum binds to protein that is being eliminated in significant amounts via the urine during the infusion, it is impossible to predict the composition of species $\mathbf{1}-\mathbf{6}$ according to the data in Figure 1 . This system is far from the chemical equilibrium. A major part (68-98\%) of cisplatin is bound to the blood plasma proteins, especially on human serum albumin (HSA) ${ }^{6}$. One molecule of HSA binds five molecules of cisplatin. cis- $\left[\mathrm{PtCl}\left(\mathrm{NH}_{3}\right)_{2}\right]^{+}$is bound to nitrogen atom from His105 and His288 and sulphur atoms from Met329, Met298 and Met548. Treatment of HSA with cisplatin also leads to the formation of adduct between cis-[ $\left.\mathrm{Pt}\left(\mathrm{NH}_{3}\right)_{2}\right]^{2+}$ and His67 and His247. Since both histidine residues are involved in the transport of $\mathrm{Zn}^{2+}$ ions to the cell by $\mathrm{HSA}^{7}$, this may be the reason why some patients on therapy with cisplatin have zinc imbalance in their body. ${ }^{8}$ For study of binding of platinum compounds to human serum proteins a novel method for accessing of $\mathrm{Pt}$ using conjoint liquid chromatography has also been developed. ${ }^{9}$

\section{Cisplatin uptake from blood into a cell}

The first step for platinum drugs to exert their therapeutic as well as toxic effects is to enter the cells. This process is complex and not completely understood. Cisplatin enters a cell mainly by passive diffusion. Uptake of cisplatin by cells was proportional to the total concentration of cisplatin in the cell culture medium up to $3 \mathrm{mM}$ concentration and was not saturable. ${ }^{10}$ The most likely candidates for passive diffusion through hydrophobic lipid bilayer are neutral species without the charge such as cisplatin and monohydroxo form (1 and $\mathbf{4}$, respectively in Figure 1). But studies with the inhibitors of active transporters suggested that there must also be other uptake mechanisms. ${ }^{11}$ Recently, a lot of attention has been given to the active modes of the uptake. ${ }^{12}$ The most likely candidates for the transport of cisplatin into a cell by facilitated diffusion are the copper transporters Ctr1 (SLC31A1) and Ctr2 (SLC31A2, copper importer). ${ }^{13}$ This transmembrane protein has an extracellular domain that is rich in methionine and histidine residues. It has been suggested that both metals, platinum and copper, use Ctr1 as their entry route into the cell although the chemistry of these two metals is quite different. Switching between different oxidation states has pivotal role in the transport of copper. Whereas copper exists in two biological oxidation states as $\mathrm{Cu}^{+}$and $\mathrm{Cu}^{2+}$ ions, the cisplatin exists only in one stable biologically accessible oxidation state with $\mathrm{Pt}^{2+}$ ion. Because platinum cannot switch between different oxidation states, the uptake of cisplatin into the cell by this protein might be blocked. An additional factor that throws doubt on Ctr (1 and 2) as a main transporter of cisplatin is the reaction of extracellular methionine residue with $\mathrm{Pt}^{2+}$ resulting in formation of a stable $\mathrm{Pt}^{2+}-\mathrm{S}$ bond, similar to the bond between $\mathrm{Pt}^{2+}$ and methionine residues in HSA. Since the transport of $\mathrm{Pt}^{2+}$ ion through Ctr would require a facile breaking and reforming of the $\mathrm{Pt}^{2+}-\mathrm{S}$ bond, the thermodynamic and kinetic parameters of this bond would exclude the $\mathrm{Ctr}$ as an entry route for cisplatin. Furthermore, cis-ammonia molecules would be lost during cisplatin transfer with Ctr due to trans effect. Additionally, excessive copper in extracellular fluid triggers an internalization and degradation of Ctr protein. This acute regulatory response has also been reported following exposure of human ovarian carcinoma cells to cisplatin, but such response was not observed in other types of cancer cells. ${ }^{14}$ Although many studies have shown that cisplatin can bind to $\mathrm{Ctr}$, none has shown that $\mathrm{Pt}^{2+}$ 
ion can actually be transported into a cell by this mechanism..$^{15}$ Arnesano and Natile ${ }^{16}$ hypothesized that the interaction of cisplatin with Ctr leads to pinocytosis and vesicular transport of cisplatin into the cell, thus protecting the drug from inactivation with glutathione (GSH) and metallothioneins (MT) which are present in cells.

As forms 2, 3 and 5 shown in Figure 1 are cations, led investigators to examine the involvement of organic cation transporters (OCTs, SLC22A) in cisplatin transport across the membrane. This assumption was strengthened by the observation that OCTs are expressed in tissues sensitive to cisplatin toxicity. It was shown that both OCT1 (SLC22A1) and OCT2 (SLC22A2) are implicated in transport of cisplatin into the HEK 293 cells as well as the other cell lines. ${ }^{17}$ Under physiological conditions, cisplatin may also undergo a transformation in cisplatin carbonato complexes, which are anionic species and these forms may be transported into the cell by organic anion transporters (OATs, SLC22A). The transport of platinum drugs by OAT may also explain the nephrotoxicity of these substances. ${ }^{18}$ Both OCT and OAT mediated cisplatin nephrotoxicities are observed in $30 \%$ of patients. OCT2 is specifically expressed in the kidneys and for this reason it is a suitable target for the investigating of the protection against nephrotoxicity. The tissue specific expression of OCT may be also critical for the development of ototoxicity as well as peripheral neurotoxicity. ${ }^{19}$

\section{Cisplatin transport out of the cells}

Since the therapeutic range of cisplatin is narrow we cannot overcome the cell resistance simply by increasing the dose. Resistance to cisplatin is a consequence of the enhanced removal of the drug that enters a cell and the efficiency of DNA repair mechanisms, which remove lethal adducts between DNA and cisplatin. Another copper transporter, $A T P 7 A$ and closely related $A T P 7 B$, which deliver copper into the organelles and are responsible for removing the excess copper out of a cell, may also be involved in the cisplatin-induced resistance. ${ }^{20}$ Mutation in ATP7B gene produces accumulation of copper in the body, a state known as Wilson's disease ${ }^{21}$, while the mutation in ATP7 A gene has the opposite effect and is responsible for a copper deficiency, known as the Menkes disease. ${ }^{22}$ Both $A T P 7 A$ and $A T P 7 B$ can bind cisplatin at cysteine residue in their N-terminal metal binding domains forming a stable $\mathrm{Pt}^{2+}-\mathrm{S}$ bond. Elevated levels of these proteins correlate with a diminished accumulation of cisplatin and consequently with lower cytotoxicity. ${ }^{23}$

Beside the copper-transporting proteins GSH and metallothioneins may also influence cisplatin transport. These cysteine rich, low molecular weight proteins are involved in intracellular inactivation of platinum and other similar drugs through coordination to thiol groups. An overexpression of metallothionein in the tumour cells is present in $70 \%$ of the patients with oesophageal cancer and it is correlated with resistance to cisplatin..$^{24}$ It was shown that GSH and cisplatin form anionic bis $\mathrm{Pt}^{2+}$ GSH complexes which can be refluxed from leukaemia cells in the presence of ATP. ${ }^{25}$ Later it was shown that multidrug resistance-associated protein MRP2 (ABCC2) and OAT were responsible for the efflux of this complex. ${ }^{26}$ Since the formation of the adduct between cisplatin and two deprotonated forms of GSH prevents the drug from reacting with DNA and other targets, MRP2 and OAT are important factors in detoxification of the cell from cisplatin. Due to combination of uptake and export transporters only $1 \%$ of administered drug reaches the site of action within the cells. Cellular traffic of cisplatin is summarized in Figure 2.

\section{Clinical applications}

\section{Genetic background as a determinant of cisplatin-based drug response}

The inter-individual variability of the efficacy of platinum based chemotherapy as well as its toxic-

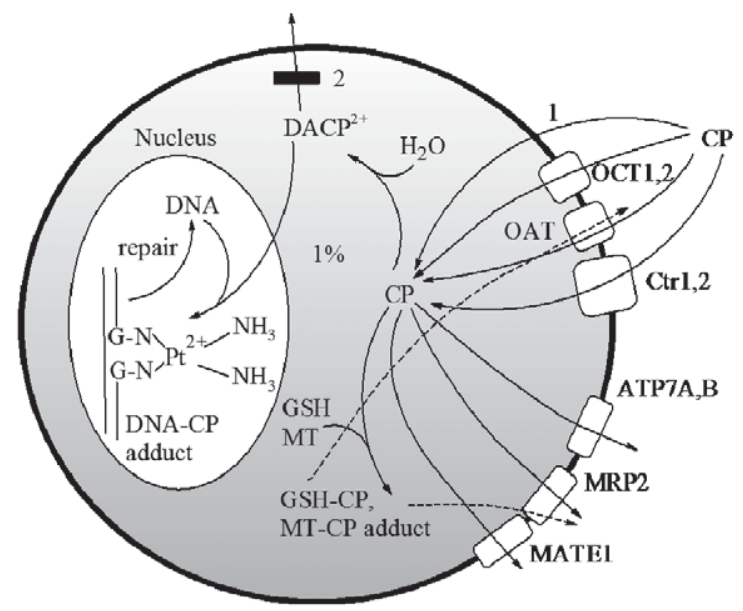

FIGURE 2. Traffic of cisplatin (CP). 1, passive diffusion, 2, passive diffusion blocked. See text for explanations. CP: cisplatin, DACP: diaqua cisplatin, OCT: organic cation transporter, OAT: organic anion transporter, Ctr: copper transporter, MRP: multidrug resistance-associated protein, ATP7: coppertransporting P-type ATPase, MATE: multidrug extrusion transporter, GSH: glutathione, MT: metallothionein. 
TABLE 1. Polymorphisms of transporters that influence the efficacy of platinum drugs

\begin{tabular}{|c|c|c|}
\hline Protein & Gene & Genetic polymorphisms or expression level (EL) that influences the outcome of platinum-based therapy \\
\hline \multicolumn{3}{|c|}{ Uptake of platinum drugs } \\
\hline OCT1 & SLC22A 1 & $\begin{array}{l}\text { c.181C>T, c. } 480 C>G, c .1022 C>T \\
c .1222 A>G, c .1390 G>A, c .1463 G>T\end{array}$ \\
\hline ОСТ2 & SLC22A2 & c. $160 \mathrm{C}>\mathrm{T}, \mathrm{c} .481 \mathrm{~T}>\mathrm{C}, \mathrm{C} .493 \mathrm{~A}>\mathrm{G}, \mathrm{C} .495 \mathrm{G}>\mathrm{A}, \mathrm{C} .808 \mathrm{G}>\mathrm{T} . \mathrm{C} .890 \mathrm{C}>\mathrm{G}, \mathrm{C} .1198 \mathrm{C}>\mathrm{T}, \mathrm{C} .1294 \mathrm{~A}>\mathrm{C}$ \\
\hline OCT3 & SLC22A3 & EL \\
\hline CTR1 & SLC3IAl & $\mathrm{rs} 10981694 \mathrm{~A}>\mathrm{C}$ \\
\hline \multicolumn{3}{|c|}{ Efflux of platinum drugs } \\
\hline MATEl & SLC47Al & p.Gly64Asp and p.Val480Met: reduced transport of oxaliplatin \\
\hline MATE2 & SLC47A2 & p.Gly211 Val \\
\hline ATP7A & ATP7A (MNK) & c.2299G > C (p.Val767Leu) and c.4390A > G (p.llel464Val) \\
\hline ATP7B & $\begin{array}{l}\text { ATP7B } \\
\text { (WND) }\end{array}$ & $\begin{array}{l}\text { c.1216G > T (p.Ala406Ser), c.1366G > C (p.Val456Leu), c.2495A > G (p.KLys32Arg), c.2785A > G } \\
\text { (p.lle929Vall), c.2855G > A (p.Arg952Lys), c.2871 delC (P957PfsX9), c.3419 T > C (p.Vall 140Ala), } \\
\text { c.3836A > G (p.Asp1279Gly), c.3886G > A (p.Aspl296Asn) and c.3889G > A (p.Vall297lle) }\end{array}$ \\
\hline
\end{tabular}

$\mathrm{EL}=$ expression level

TABLE 2. Polymorphisms of DNA-platinum drug adducts repairing enzymes

\begin{tabular}{lll}
\hline Protein & \multicolumn{1}{c}{ Gene } & Polymorphisms \\
\hline \multicolumn{2}{l}{ DNA-adduct repair system } & \\
\hline ERCC1 & ERCC1 & C.8092C>A, C.C354T \\
XRCC1 & $X R C C 1$ & c.C580T, C.A1196G \\
XRCC3 & XRCC2 & p.Thr241Met, C.C241T \\
XPD & $X P D$ & P.Lys751 Gln, C.A2251C, C.C2133T \\
XPG & & C.T242C \\
XPA & & 5'UTR \\
\hline Metabolism of platinum-based drugs & \\
\hline MDR1 & & C.T3435C \\
GSTP1 & GSTP1 (FAEES3) & C.A313G \\
\hline
\end{tabular}

ity is the result of the genetic variability in genes involved in drug metabolism, drug transport and DNA repair. Therefore, the determination of genetic markers such as genetic polymorphisms in these genes may provide the hints about the optimal cisplatin regimens for personalized therapy.

Both uptake and efflux transporters are subject to genetic variability. Polymorphic transporters are involved in processes that increase the intracellular level of the drug: transport with copper transporters Ctr1 and 2 and organic cation transporters OCT 1 and 2. The same is true for the transporters that are involved in the efflux of cisplatin from the cell and resistance, copper-transporting ATPases ATP7A and ATP7B, organic anion transporters, $\mathrm{OAT}$, glutathione and metallothionein, multidrug resistance-associated protein MRP2 as well as multidrug extrusion transporter-1 (MATE1). ${ }^{27}$
The presence of single nucleotide polymorphisms in all transporters shown in Figure 2 influence the response of patients to platinum drugs in a great extent and this influence is dependent on both, the type of platinum drug and the type of cancer cells. ${ }^{28}$ The data on these polymorphisms are summarized in the Table 1.

The main mechanism of resistance is a DNAplatinum drug adducts repairing system. Polymorphisms of DNA-adduct repair enzymes also play a role in sensitivity towards platinumbased chemotherapy (Table 2). X-ray repair crosscomplementing group 1 (XRCC1), excision repair cross complementation 1 (ERCC1) and xeroderma pigmentosum complementary group (XPA, XPD and $\mathrm{XPG}$ ) are enzymes that play the crucial role in these processes. The polymorphic A1196G allele in XRCC1 gene is present in $20-38 \%$ of lung cancer patients. ${ }^{29} \mathrm{~A}$ number of studies have been performed to investigate the association of XRCC1 gene polymorphisms with platinum drug efficacy but the results are inconsistent.

Recent studies also investigated Major Vault Protein (MVP) present as the main component of the vault in normal tissues as well as in malignant cells, including ovarian cancer, colon carcinoma and acute myeloid leukaemia. ${ }^{30}$ Although MVP has been linked to the development of multidrug resistance in cancer cells, several studies have reported conflicting results. ${ }^{31}$ The association between polymorphisms in MVP gene and platinum resistance has not yet been confirmed probably due to the limited number of patients. ${ }^{32}$ 


\section{Allergic reactions to cisplatin}

Although allergic reactions to cisplatin are rare, with later cisplatin derivatives, carboplatin and oxaliplatin the allergic reactions are more common. Still they are less frequent than with anticancer drugs which names end with "mab" and other drugs that contain proteins. Hypersensitivity reactions to platinum generally occur after multiple cycles of therapy - they are acquired and are consistent with type 1 IgE-mediated hypersensitivity. In patients presenting with severe hypersensitivity reactions to carboplatin it is feasible to replace it with cisplatin. Overall incidence of hypersensitivity to platinum agents is $5-20 \%$ for cisplatin and occurs mostly between $4^{\text {th }}-8^{\text {th }}$ course of infusion. The incidence is $1-44 \%$ for carboplatin and $10-$ $20 \%$ for oxaliplatin. ${ }^{33}$ The most striking difference between carboplatin hypersensitivity, compared to hypersensitivity to nonplatinum drugs, is that the cumulative risk of hypersensitivity reactions increases with the number of infusions and there is no evidence of plateau. ${ }^{34}$ Hypersensitivity reactions occur more frequently in patients receiving certain drug combinations such as carboplatin paclitaxel as compared to carboplatin in combination with pegylated lyposomal doxorubicin. ${ }^{35}$

\section{Cisplatin and multimodal treatment and novel approaches}

Since hyperthermia enhances cytotoxic effects of cisplatin, the trimodal combination of platinum drugs with hyperthermia and radiation can lead to potent synergistic interaction. ${ }^{36}$ There is a synergistic effect of regional hyperthermia $\left(39-43^{\circ} \mathrm{C}\right)$ and cisplatin anti-tumour efficacy, if cisplatin is encapsulated in temperature-sensitive liposomes used for targeted drug delivery. It is hypothesized that hyperthermia increases cisplatin accumulation in part by increasing Ctr1 multimerization and thus greater cisplatin accumulation. Increased Ctr1 multimerization following hyperthermia treatment $\left(41^{\circ} \mathrm{C}\right)$ in vitro, compared to normothermic controls $\left(37^{\circ} \mathrm{C}\right)$, was observed suggesting that there may be a mechanism for an increased cisplatin uptake in heat-treated cells. Hyperthermia enhanced cisplatin-mediated cytotoxicity in wild type (WT) cells with a dose modifying factor (DMF) of 1.8 compared to 1.4 in Ctr1-/- cells because WT cells contained greater levels of platinum compared to Ctr1-/- cells. ${ }^{37}$

Since the atomic number of platinum is high, 78, it is possible to produce Auger electrons and/ or Auger radiation upon treating the platinum drug with ionizing radiation. Treatment of cervical cancer with a conjunction of cisplatin and ionizing radiation increased survival and disease free intervals and became a part of standard care for the treatment of cervical cancers. ${ }^{38}$ The »Trojan horse « treatment of glioblastoma involves gold (atomic number 79) nanoparticles and attached molecules of cisplatin. Treated cultured glioblastoma cells in preclinical studies absorb nanoparticles and DNA binds platinum attached to nanoparticles. After radiation, both gold and platinum serve as high atomic number radio sensitizers that emit Auger electrons and radiation. The resulting assembly of gold nanoparticles with attached cisplatin and antibodies after radiation exhibit both chemotherapeutic power to cancer cells as well as Augermediated secondary electron emission, which cause DNA double strand breaks adjacent to the cisplatin bound to DNA. ${ }^{39}$ Binding cisplatin to gold nanoparticles is also a strategy to enhance the delivery of cisplatin through the blood brain barrier. A combination with a magnetic resonance-guided ultrasound intensifies glioblastoma treatment. It is demonstrated that the assembly of gold nanoparticles and cisplatin greatly inhibits the growth of glioblastoma cells compared to the free cisplatin and synergy with radiation therapy. ${ }^{40}$ An important reactive oxygen species (ROS) scavenger DJ1 protein (PARK7) modulates different oncogenic pathways that support the growth and invasion of ovarian cancer cells. This cancer targeted nanoplatform based on siRNA-mediated suppression of DJ1 protein outperforms cisplatin alone. Three cycles of siRNA-mediated DJ-1 therapy combined with a low dose of cisplatin completely eradicated ovarian cancer tumours from the mice without recurrence during a 35-week long study. ${ }^{41}$

The next step in the research includes the attachment of the transport system for delivering nanoparticles with cisplatin to the target. ${ }^{42}$ Mice treated with hyaluronic-acid conjugated mesoporous silica nanoparticles carried TWIST-siRNA and cisplatin exhibited specific tumour targeting and reduction of tumour burden. ${ }^{43}$

Another important aspect of novel approaches to cisplatin chemotherapy is to reduce cisplatin toxicity. The two other approved platinum-based chemotherapeutics, carboplatin and oxaliplatin exhibit improved nephrotoxicity ${ }^{44}$ and ototoxicity ${ }^{45}$ profiles, but are also less efficient than cisplatin. This challenge could be addressed by harnessing a nanotechnology-based strategy. An example of the cisplatin toxicity prevention on the reproduc- 
tive system is the use of selenium nanoparticles (Nano-Se). Nano-Se particles, due to their strong antioxidant potential are suitable to prevent cisplatin induced gonadotoxicity. Co-administration with cisplatin significantly improves the sperm quality, serum testosterone and spermatogenesis in male rats. ${ }^{46}$ Lipoplatin is another example of bias cisplatin toxicity. These nanoparticles of $110 \mathrm{~nm}$ average diameter are composed of lipids and cisplatin. After intravenous administration it escapes clearance from macrophages and the half-life of lipoplatin is 120 h. ${ }^{47}$ Attachment of platinum drugs to nanoparticles passively targets solid tumours through the enhanced permeability. Lipoplatin exerted negligible nephrotoxicity, ototoxicity and neurotoxicity in Phase I human studies. ${ }^{48}$

For poorly permeable platinum drugs such as cisplatin and similar low lipophilic analogues, a higher doses are needed to exert therapeutic effect and consequently toxicity is more pronounced. To mitigate this effect an enhanced influx into the cancer cells can be achieved with electroporation in the process of electrochemotherapy. ${ }^{49,50,51}$ This method increases the cytotoxicity up to 80 -fold in cisplatin-sensitive as well as cisplatin-resistant tumour types. $^{52}$ Other approach include the synthesis of novel platinum compounds with more lipophilic leaving groups with potential antitumor effect. One such candidate is trans-[ $\mathrm{PtCl}_{2}$ (3-hydroxymethylpyridine $)_{2}$ ] applied with electroporation as drug delivery method ${ }^{53}$.

\section{Non-DNA targets for cisplatin}

The principle target of cisplatin is the DNA as the platination of the DNA is lethal to the cell. However, the other targets are also very important and may contribute to the lethal effect on the cell. Cisplatin, among others, attacks mitochondria and triggers the production of ROS, destroys lysosomes inducing the release of lysosomal proteases and degrades endoplasmic reticulum which results in the deregulation of calcium storage and in the misfolded proteins. ${ }^{54}$ Beside the DNA in mitochondria, cisplatin attacks other organelles by forming adducts with functional groups on proteins, especially with the sulphur atom in cysteine and methionine side chains.

A membrane-bound $\mathrm{Na}^{+} / \mathrm{H}^{+}$exchanger protein (NHE) is one of the non-DNA targets for cisplatin. When cisplatin binds to this protein in human colon cancer cells, it causes intracellular acidosis, increases fluidity of membrane through promotion of lipid rafts and the induction of apoptosis via fas pathway and cell death. ${ }^{55}$ Since the membrane is the first barrier that cisplatin must cross, NHE may be the first target for cisplatin in cancer cells. Adducts between NHE and cisplatin occur in a few minutes after adding cisplatin to the culture medium, whereas cisplatin-DNA adducts occur at a much slower rate after about an hour.

Zinc fingers that bind to the DNA and regulate gene expression are also cisplatin targets. An example is 31-amino-amino-acid long zinc finger, that is the DNA-binding domain of the enzyme DNA-polymerase-a, a very important enzyme for accurate synthesis of genetic information. ${ }^{56}$ Four thiolate groups from cysteine residues coordinate the zinc atom in zinc fingers. Cisplatin reacts with the $\mathrm{Zn}^{2+}$ ion in a stepwise manner to substitute the coordinated $\mathrm{Zn}^{2+}$ ion from the finger. The reaction between a zinc finger and cisplatin is faster than between cisplatin and DNA. That means that the zinc fingers could be the targets for platinum drugs. Cisplatin changes the structure of DNApolymerase-a and this could be the mechanism by which the drug blocks DNA replication and causes cell death.

Another protein target is tubulin. These $50 \mathrm{kDa}$ proteins must be assembled into microtubules and disassembled rapidly during mitosis and molecules that interfere with this process can push the cell into a cell-cycle arrest and the cell dies. Even in the presence of an anticancer drug paclitaxel, which stabilizes and prevents disassembly of microtubules into tubulin, the nonfilamentous structures appear only if the diaqua derivative of cisplatin is present. GTP is required for the formation of filaments and since platinum drugs react readily with N7-atom in guanine, this is the mechanism of the deprivation of the necessary energy for the microtubule formation. ${ }^{57}$

Thioredoxin reductase (TrxR) has selenocysteine residue at the C-terminus that is an excellent target for platinum drugs. Both cisplatin and transplatin can irreversibly inactivate this enzyme. Since a large percent of cisplatin in the cell is inactivated by GSH into GS-Pt, Ishikawa surprisingly found that GS-Pt can also inactivate TrxR. ${ }^{58}$ In the presence of cisplatin, cells also produce increased level of stress response and DNA-binding proteins.

RNA is another molecule that has been largely overlooked as a possible candidate for the cisplatin attack and also contains suitable positioned bases. DeRose with the co-workers have shown that 4 to 20-fold more platinum binds to RNA compared to DNA. ${ }^{59}$ Helix 18 of $18 S$ rRNA binds three platinum 
ions. One of them is bridging opposing strands of RNA in an interstrand crosslink.

\section{Cytotoxic metals}

The problem with cisplatin is that it may be inactivated into transplatin during the uptake into the cell via Ctr1 transporter. To avoid this problem other derivatives of platinum drugs have been synthesized, where two ligands are interconnected and trans effect is decreased. Oxaliplatin, nedaplatin, lobaplatin, heptaplatin and carboplatin have both oxygen ligands in one molecule as bidentate ligand. Oxaliplatin, lobaplatin and heptaplatin have also nonleaving amino ligands as parts of the bidentate molecule.

The next generation of cisplatin-like drugs tend to be structurally similar to the approved drugs and they are expected to operate via a similar mechanism of action. More than five thousand distinct compounds with general formula cis- $\mathrm{PtA}_{2} \mathrm{X}_{2}$, where $A$ is the symbol for ammine or a substituted ammine and $\mathrm{X}$ is anionic bidentat ligand, have been synthesized until now. The effort put into the elucidation of mechanisms of tumour resistance to cisplatin and other platinum based drugs triggered the boom also in other metal based cytostatics.

During a 40-year-long period between the development and the final approval of cis-, carbo- and oxaliplatin, the search for nonplatinum anticancer drugs yielded some interesting compounds. Better understanding of their chemistry and mode of action may facilitate the development of anticancer drugs based on these compounds.

Ruthenium Organometallic ruthenium (II) arene compounds are emerging as a new class of promising anticancer drugs. They show selective activity against certain cancer cells and low toxicity. Due to octahedral coordination sphere, ruthenium complexes have higher degree of specificity and size discrimination and exert lower toxicity and faster elimination from the body, in contrast to square planar geometry of platinum (II) compounds. Well known species NAMI-A and KP1019, which are currently in clinical trials, is opening new approaches in cancer treatment. The cellular targets of ruthenium compounds have not yet been identified with certainty. Despite the fact that DNA has been assumed to be the primary target, recent results show that several proteins have been recognized as the binding partners..$^{60}$ In particular, these proteins are glutathione S-transferase, HSA and transferin. ${ }^{61}$ NAMI-A binds to the exposed imida- zole (histidine) on HSA and apo-transferrin, but only weakly on DNA and RNA. The main effect of NAMI-A is to stop a tumour from spreading, a process known as metastasis. ${ }^{60}$

Gold, palladium. In arthritic patients receiving gold +3 and +1 compounds as therapy it was observed that gold possesses anticancer activity. ${ }^{62}$ The mechanism of the action of gold compounds, for example a gold phosphine ligands $\left[\mathrm{Au}(\mathrm{dppe})_{2}\right]^{+}$, is still unknown, although, most researchers believe that the site of action of this compound is the mitochondria in the cells. Such compounds also produce breaks in DNA and also serve as a bridge between protein and DNA. Complexes with gold and palladium, depending on dose, reduce the proliferation of ovarian and breast cancer as well as myeloid leukaemia and lymphatic cell line. Compounds with selenium ligands in general induce stronger effects than compounds with sulphur ligands. The IC $50^{1}$ for proliferation of SUP-B15 cells was 50\% lower with Au-Se compounds in comparison with Au-S compounds and around a quarter lower in the case of Ru-Se and Pd-Se compounds in comparison with Ru-S and Pd-S compounds. ${ }^{63}$ The mechanism of action is composed of the inhibition of metabolism and proliferation and it also includes apoptosis and oxidative stress by ROS production.

In titanium, as in cisplatin, there are two chloride-leaving ligands in cis position present in titanocene dichloride and the molecule is neutral in charge. Since this compound showed no nephroor myelotoxicity in preclinical studies, it was entered into clinical trials. ${ }^{64}$ The trials revealed that the compound was active against colon 38 carcinoma and B16 melanoma cells. In treating ovarian cancer cells, titanocene dichloride displayed higher activity than cisplatin. While investigating the mechanism of action, a far more complicated picture has appeared indicating multiple cellular processes that can be triggered by titanium anticancer compounds. ${ }^{65}$ The exact site of binding is not established, but since $\mathrm{Ti}^{4+}$ is a hard base, negatively charged oxygens on the phosphate groups of DNA form bonds with the ion and thus disable DNA. ${ }^{66}$

Vanadium, niobium, molybdenum and rhenium complexes - early transition metal based antitumor drugs and a large spectrum of other transition metals have also been tested for anticancer activity. For most of them, the intercalation with DNA atoms is not required for activity. Proteins, such as human topoisomerase 1 and thioredoxin reductase, are only a few of the possible targets of these transition metal complexes. ${ }^{67}$ 


\section{Conclusions}

In the last decade, several of platinum and other metal complexes have been created and tested for anticancer activity in order to bypass the drawback of existing metal anticancer chelates. The enormous spectrum of transition metal combinations and a plethora of ligands combinations have produced extremely broad spectrum of anticancer complexes - more than 5000 only with platinum. Each of them has its own mechanism of action and the continuation of work on this field could produce metal complexes which can outperform the existing drugs and provide more effective chemotherapy and less toxicity.

The other field of intensive research is the investigation of genetic polymorphisms as an approach to the optimal metal-based chemotherapy for a particular individual and probably it represents the plateau of this type of treatment. The solid knowledge of the molecular mechanisms of action and genetic basis of interindividual variability of response to cisplatin and other metal based compounds summarized in this review may therefore help the oncologist to better understand the mechanism of their cytostatic action.

\section{References}

1. Rosenberg B, Van Camp L, Grimley EB, Thomson AJ. The inhibition of growth or cell division in Escherichia coli by different ionic species of platinum(IV) complexes. J Biol Chem 1967; 242: 1347-52. PMID: 5337590

2. Rosenberg B. Van Camp L, Trosko JE, Mansour VH. Platinum compounds: a new class of potent antitumor agents. Nature 1969; 222: 385-6. PMID: 5782119

3. Peyrone M. Über die einwirkungdes ammoniaks auf platichlorür. Annalen der chemie und pharmacie 1844; 51: 1-29. doi: 10.1002/jlac.18440510102

4. Rosenberg B. Some biological effects of platinum compounds. New agents for the control of tumours. Platinum Met Rev 1971; 15: 42-51.

5. Apps MG, Choi EHY, Wheate NJ. The state-of-play and future of platinum drugs. Endocr Relat Cancer 2015; 22: R219-33. doi: 10.1530/ERC-15-0237

6. Dabrowiak JC. Metals in medicine. 2nd edition. John Wiley \& Sons Ltd; 2017. p. 94-5

7. Sooriyaarachchi M, Narendran A. Gailer J. Comparative hydrolysis and plasma protein binding of cisplatin and carboplatin in human plasma in vitro. Metallomics 2011; 3: 49-55. doi: 10.1039/c0mt00058b

8. Handing KB, Shabalin IG, Kassaar O, Khazaipoul S, Blindauer CA, Stewart AJ, et al. Circulatory zinc transport is controlled by distinct interdomain sites on mammalian albumins. Chem Sci Chem 2016; 7: 6635-48. doi: 10.1039/ c6sc02267g

9. Hu W, Luo Q, Wu K, Li X, Wang F, Chen Y, et al. The anticancer drug cisplatin can crosslink the interdomain zinc site on human albumin. Chem Commun (Camb) 2011; 47: 6006-8. doi: 10.1039/c1cc11627d

10. Martinčič $A$, Cemazar $M$, Serša G, Kovač V, Milačič R, Ščančar J. A novel method for speciation of Pt in human serum incubated with cisplatin, oxaliplatin and carboplatin by conjoint liquid chromatography on monolithic disks with UV and ICP-MS detection. Talanta 2013; 116: 141-8. doi: 10.1016/j.talanta.2013.05.016
11. Eljack ND, Ma HY, Drucker J, Shen C, Hambley TW, New EJ, et al. Mechanisms of cell uptake and toxicity of the anticancer drug cisplatin. Metallomics 2014; 6: 2126-33. doi: 10.1039/c4mt00238e

12. Hall MD, Okabe M, Shen DW, Liang XJ, Gottesman MM. The role of cellular accumulation in determining sensitivity to platinum-based chemotherapy. Annu Rev Pharmacol Toxicol 2008; 48: 495-535. doi: 10.1146/annurev. pharmtox.48.080907.180426

13. Eljack ND, Ma MH, Drucker J, Shen C, Hambley TW, New JE, et al. Mechanisms of cell uptake and toxicity of the anticancer drug cisplatin. Metallomics 2014; 6: 2126-33. doi: 10.1039/c4mt00238e

14. Lasorsa A, Natile G, Rosato A, Tadini-Buoninsegni F, Arnesano F. Monitoring interactions inside cells by advanced spectroscopies: overview of copper transporters and cisplatin. Curr Med Chem 2018; 25: 462-77. doi: 10.2174/ 0929867324666171110141311

15. Holzer AK, Howell SB. The internalization and degradation of human copper transporter 1 following cisplatin exposure. Cancer Res 2006; 66: 10944-52. doi: 10.1158/0008-5472.CAN-06-1710

16. Ivy KD, Kaplan JH. A re-evaluation of the role of hCTR1, the human highaffinity copper transporter, in platinum-drug entry into human cells. Mol Pharmacol 2013; 83: 1237-46. doi: 10.1124/mol.113.085068.

17. Arnesano F, Seintilla $S$, Natile G. Interaction between platinum complexes and a methionine motif found in copper transport proteins. Angew Chem Int Ed Eng/ 2007; 46: 9062-4. doi: 10.1002/anie.200703271

18. Yonezawa A, Masuda S, Yokoo S, Katsura T, Inui K. Cisplatin and oxaliplatin, but not carboplatin and nedaplatin, are substrates for human organic cation transporters (SLC22A1-3 and multidrug and toxin extrusion family). J Pharmacol Exp Ther 2006; 319: 879-86. doi: 10.1124/jpet.106.110346

19. Nieskens TTG, Peters JGP, Dabaghie D, Korte D, Jansen K, Van Asbeck AH, et al. Expression of organic anion transporter 1 or 3 in human kidney proximal tubule cells reduces cisplatin sensitivity. Drug Metab Dispos 2018; 46: 5929. doi: 10.1124/dmd.117.079384

20. Ciarimboli G. Membrane transporters as mediators of cisplatin side-effects. Anticancer Res 2014; 34: 547-50. PMID: 24403515

21. Calandrini V, Arnesano F, Galliani A, Nguyen TH, Ippoliti E, Carloni P, et al. Platination of the copper transporter ATP7A involved in anticancer drug resistance. Dalton Trans 2014; 43: 12085-94. doi: 10.1039/c4dt01339e

22. Aggarwal A, Bhatt M. Advances in treatment of Wilson disease. Tremor Other Hyperkinet Mov (NY) 2018; 8: 525. doi: 10.7916/D841881D

23. Ferreira CR, Gahl WA. Disorders of metal metabolism. Transl Sci Rare Dis 2017; 2: 101-39. doi: 10.3233/TRD-170015

24. Tadini-Buoninsegni F, Bartolommei G, Moncelli MR, Inesi G, Galliani A Sinisi M, et al. Translocation of platinum anticancer drugs by human copper ATPases ATP7A and ATP7B. Angew Chem Int Ed Engl 2014; 53: 1297-301. doi: 10.1002/anie.201307718

25. Hishikawa $\mathrm{Y}$, Abe $\mathrm{S}$, Kinugasa $\mathrm{S}$, Yoshimura $\mathrm{H}$, Monden $\mathrm{N}$, Igarashi $\mathrm{M}$, et al Overexpression of metallothionein correlates with chemo resistance to cisplatin and prognosis in oesophageal cancer. Oncology 1997; 54: 342-7. doi: $10.1159 / 000227714$

26. Ishikawa T, Ali-Osman F. Glutathione-associated cisdiamminedichloroplatinum(II) metabolism and ATP-dependent efflux from leukaemia cells. Molecular characterization of glutathione-platinum complex and its biological significance. J Biol Chem 1993; 268: 20116-25. PMID: 8376370.

27. Chen HH, Kuo MT. Role of glutathione in the regulation of cisplatin resistance in cancer chemotherapy. Met Based Drugs 2010; pii: 430939. doi: $10.1155 / 2010 / 430939$

28. Sauzay C, White-Koning M, Hennebelle I, Deluche T, Delmas C, Imbs DC, et al. Inhibition of OCT2, MATE1 and MATE2-K as a possible mechanism of drug interaction between pazopanib and cisplatin. Pharmacol Res 2016; 110: 89-95. doi: 10.1016/j.phrs.2016.05.012

29. Sprowl JA, Ness RA, Sparreboom A. Polymorphic transporters and platinum pharmacodynamics. Drug Metab Pharmacokinet 2013; 28: 19-27. PMID: 22986709

30. Filipski KK, Mathijssen RH, Mikkelsen TS, Schinkel AH, Sparreboom A. Contribution of organic cation transporter 2 (OCT2) to cisplatin-induced nephrotoxicity. Clin Pharmacol Ther 2009; 86: 396-402. doi: 10.1038/ clpt.2009.139 
31. Tzvetkov MV, Behrens G, O’Brien VP, Hohloch K, Brockmöller J, Benöhr P. Pharmacogenetic analyses of cisplatin-induced nephrotoxicity indicate a renoprotective effect of ERCC1 polymorphisms. Pharmacogenomics 2011 12: 1417-27. doi: 10.2217/pgs.11.93

32. Hsu CM, Lin PM, Chang JG, Lin HC, Li SH, Lin SF, et al. Upregulated SLC22A3 has a potential for improving survival of patients with head and neck squamous cell carcinoma receiving cisplatin treatment. Oncotarget 2017; 8: 74348-58. doi: 10.18632/oncotarget.20637

33. Chen Y, Teranishi K, Li S, Yee SW, Hesselson S, Stryke D, et al. Genetic variants in multidrug and toxic compound extrusion-1, hMATE1, alter transport function. Pharmacogenomics J 2009; 9: 127-36. doi: 10.1038/tpj.2008.19

34. Au WW, Salama SA, Sierra-Torres CH. Functional characterization of polymorphisms in DNA repair genes using cytogenetic challenge assays. Environ Health Perspect 2003; 111: 1843-50. doi: 10.1289/ehp.6632

35. Osawa K. Gene polymorphisms and chemotherapy in non-small cell lung cancer. Zhongguo Fei Ai Za Zhi 2009; 12: 837-40. doi: 10.3779/j. issn.1009-3419.2009.08.01

36. de las Peñas R, Sanchez-Ronco M, Alberola V, Taron M. Camps C, GarciaCarbonero R, et al. Polymorphisms in DNA repair genes modulate survival in cisplatin/gemcitabine-treated non-small-cell lung cancer patients. Ann Oncol 2006; 17(4): 668-75. doi: 10.1093/annonc/mdj135

37. Saldivar JS, Lu KH, Liang D, Gu J, Huang M, Vlastos AT, et al. Moving toward individualized therapy based on NER polymorphisms that predict platinum sensitivity in ovarian cancer patients. Gynecol Oncol 2007; 107(1 Suppl 1): S223-9. doi: 10.1016/j.ygyno.2007.07.024

38. Goričar K, Kovač V, Jazbec J, Zakotnik B, Lamovec J, Dolžan V. Genetic variability of DNA repair mechanisms and glutathione-S-transferase genes influences treatment outcome in osteosarcoma. Cancer Epidemiol 2015; 39: 182-8. doi: 10.1016/j.canep.2014.12.009

39. Deng JH, Deng J, Shi DH, Ouyang XN, P.-G. Niu PG. Clinical outcome of cisplatin-based chemotherapy is associated with the polymorphisms of GSTP1 and XRCC1 in advanced nonsmall cell lung cancer patients. Clin Transl Oncol 2015; 17: 720-6. doi: 10.1007/s12094-015-1299-6

40. Izquierdo MA, Scheffer GL, Flens MJ, Giaccone G, Broxterman HJ, Meijer $\mathrm{CJ}$, et al. Broad distribution of the multidrug resistance-related vault lung resistance protein in normal human tissues and tumours. Am J Pathol 1996; 148: 877-87. PMID: 8774142

41. Sedláková I, Laco J, Caltová K, Červinka M, Tošner J, Řezáč A, et al. Clinical significance of the resistance proteins LRP, Pgp, MRP1, MRP3, and MRP5 in epithelial ovarian cancer. Int J Gynecol Cancer 2015; 25(2): 236-43. doi: 10.1097/IGC.0000000000000354

42. Zhao YN, He DN, Wang YD, Li JJ, Ha MW. Association of single nucleotide polymorphisms in the MVP gene with platinum resistance and survival in patients with epithelial ovarian cancer. Oncol Lett 2016; 11(4): 2925-33. doi 10.3892/ol.2016.4311

43. Makrilia N, Syrigou E, Kaklamanos I, Manolopoulos L, Wasif Saif M. Hypersensitivity reactions associated with platinum antineoplastic agents: a systematic review. Metal-Based Drugs 2010; 2010: 1-11. doi: $10.1155 / 2010 / 207084$

44. Lafay-Cousin L, Sung L, Carret AS, Hukin J, Wilson B, Johnston DL, et al. Carboplatin hypersensitivity reaction in paediatric patients with low-grade glioma: a Canadian paediatric brain tumour consortium experience. Cancer 2008; 112: 892-9. doi: 10.1002/cncr.23249

45. Markman M, Moon J, Wilczynski S, Lopez AM, Rowland KM Jr, Michelin DP, et al. Single agent carboplatin versus carboplatin plus PEGylated liposomal doxorubicin in recurrent ovarian cancer: final survival results of a SWOG (S0200) phase 3 randomized trial. Gynecol Oncol 2010; 116: 323-5. doi: 10.1016/j.ygyno.2009.11.026

46. van Meerten E, Franckena M, Wiemer E, van Doorn L, Kraan J, Westermann $A$, et al. Phase I study of cisplatin, hyperthermia, and lapatinib in patients with recurrent carcinoma of the uterine cervix in a previously irradiated area. Oncologist 2015; 20: 241-2. doi: 10.1634/theoncologist.2014-0365

47. Landon CD. Enhancing cisplatin delivery and anti-tumour efficacy using hyperthermia. [Dissertation]. Durcham: Duke University; 2013.

48. Rose PG, Bundy BN, Watkins EB, Thigpen JT, Deppe G, Maiman MA, et al. Concurrent cisplatin-based radiotherapy and chemotherapy for locally advanced cervical cancer. N Engl J Med 1999; 340: 3144-53. doi: 10.1056/ NEJM199904153401502
49. Biston MC, Joubert A, Adam JF, Elleaume H, Bohic S, Charvet AM, et al. Cure of Fisher rats bearing radio resistant $\mathrm{F} 98$ glioma treated with cis-platinum and irradiated with monochromatic synchrotron X-rays. Cancer Res 2004; 64: 2317-23. doi: 10.1158/0008-5472.CAN-03-3600

50. Coluccia D, Figueiredo CA, Wu MY, Riemenschneider AN, Diaz R, Luck A, et al. Enhancing glioblastoma treatment using cisplatin-gold-nanoparticle conjugates and targeted delivery with magnetic resonance-guided focused ultrasound. Nanomedicine 2018; 14: 1137-48. doi: 10.1016/j. nano.2018.01.021

51. Schumann C, Chan S, Millar JA, Bortnyak Y, Carey K, Fedchyk A, et al. Intraperitoneal nanotherapy for metastatic ovarian cancer based on siRNAmediated suppression of DJ-1 protein combined with a low dose of cisplatin. Nanomedicine 2018; 14: 1395-405. doi: 10.1016/j.nano.2018.03.005

52. Setua S, Ouberai M, Piccirillo SG, Watts C, Welland M. Cisplatin-tethered gold nanospheres for multimodal chemo-radiotherapy of glioblastoma. Nanoscale 2014; 6: 10865-73. doi: 10.1039/c4nr03693j

53. Shahin SA, Wang R, Simargi SI, Glackin CA. Hyaluronic acid conjugated nanoparticle delivery of siRNA against TWIST reduces tumour burden and enhances sensitivity to cisplatin in ovarian cancer. Nanomedicine 2017; 13: 965-76. doi: 10.1016/j.nano.2018.04.00

54. Joybari AY, Sarbaz S, Azadeh P, Mirafsharieh SA, Rahbari A, Farasatinasab $M$, et al. Oxaliplatin-induced renal tubular vacuolization. Ann Pharmacother 2014; 4: 796-800. doi: 10.1177/1060028014526160

55. Hellberg V, Wallin I, Eriksson S, Hernlund E, Jerremalm E, Berndtsson M, et al. Cisplatin and oxaliplatin toxicity: importance of cochlear kinetics as a determinant for ototoxicity. I Nat/ Cancer Inst 2009; 101: 37-47. doi: 10.1093/jnci/djn418

56. Hosnedlova B, Kepinska M, Skalickova S, Fernandez C, Ruttkay-Nedecky B, Peng Q, et al. Nano-selenium and its nanomedicine applications: a critical review. Int J Nanomedicine 2018; 13: 2107-28. doi: 10.2147/IJN.S157541

57. Boulikas T, Stathopoulos GP, Volakakis N, Vougiouka M. Systemic Lipoplatin infusion results in preferential tumor uptake in human studies. Anticancer Res 2005; 25: 3031-40. PMID: 16080562

58. Serinan E, Altun Z, Aktaş S, Çeçen E, Olgun N. Comparison of cisplatin with lipoplatin in terms of ototoxicity. J Int Adv Otol 2018; 14: 211-5. doi: 10.5152/iao.2018.4097

59. Serša G, Čemažar M, Miklavčič D. Antitumor effectiveness of electrochemotherapy with cis-diamminedichloroplatinum(II) in mice. Cancer Res 1995; 55: 3450-5. PMID: 7614485

60. Serša G, Stabuc B, Cemazar M, Miklavcic D, Rudolf Z. Electrochemotherapy with cisplatin: Clinical experience in malignant melanoma patients. Clin Cancer Res 2000; 6: 863-7. PMID: 107417

61. Gehl J, Sersa G, Wichmann Matthiessen L, Muir T, Soden D, Occhini A, et al. Updated standard operating procedures for electrochemotherapy of cutaneous tumours and skin metastases. Acta Oncol 2018, 57: 874-882. doi: 10.1080/0284186X.2018.1454602.

62. Kranjc S, Cemazar M, Sersa G, Scancar J, Grabner S. In vitro and in vivo evaluation of electrochemotherapy with trans-platinum analogue trans- $\left[\mathrm{PtCl}_{2}(3-\right.$ $\mathrm{Hmpy}_{2}$ ]. Radiol Oncol 2017; 51: 295-306. doi: 10.1515/raon-2017-0034

63. Grabner S, Modec B, Bukovec N, Bukovec P, Čemažar M, Kranjc S, et al. Cytotoxic trans-platinum(II) complex with 3-hydroxymethylpyridine: Synthesis, X-ray structure and biological activity evaluation. J Inorg Biochem 2016; 161: 40-51. doi: 10.1016/j.jinorgbio.2016.04.031

64. Sancho-Martínez SM, Prieto-García L, Prieto M, López-Novoa JM, LópezHernández FJ. Subcellular targets of cisplatin cytotoxicity: an integrated view. Pharmacol Ther 2012; 136: 35-55. doi: 10.1016/j.pharmthera.2012.07.003

65. Rebillard A, Tekpli X, Meurette O, Sergent O, LeMoigne-Muller G, Vernhet L, et al. Cisplatin-induced apoptosis involves membrane fluidification via inhibition of NHE1 in human colon cancer cells. Cancer Res 2007; 67: 7865-74. doi: 10.1158/0008-5472.CAN-07-0353

66. Bose RN, Yang WW, Evanics F. Structural perturbation of a C4 zinc-finger module by cis-diamminedichloroplatinum(II): insights into the inhibition of transcription processes by the antitumor drug. Inorganica Chim Acta 2005; 358: 2844-54. doi: org/10.1016/j.ica.2004.06.052

67. Huang X, Huang R, Gou S, Wang Z, Liao Z, Wang H. Combretastatin A-4 analogue: a dual-targeting and tubulin inhibitor containing antitumor $\mathrm{Pt}(\mathrm{IV})$ moiety with a unique mode of action. Bioconjugate Chem 2016; 27: 213248. doi: 10.1021/acs.bioconjchem.6b00353 
68. Ishikawa T, Ali-Osman F. Glutathione-associated cis-diamminedichloroplatinum(II) metabolism and ATP-dependent efflux from leukaemia cells. Molecular characterization of glutathione-platinum complex and its biological significance. J Biol Chem 1993; 268: 20116-25. PMID: 8376370

69. Hostetter AA, Osborn MF, DeRose VJ. RNA-Pt adducts following cisplatin treatment of Saccharomyces cerevisiae. ACS Chem Biol 2012; 7: 218-25. doi: 10.1021/cb200279p

70. Wolters DA, Stefanopoulou M, Dyson PJ, Groessl M. Combination of metallomics and proteomics to study the effects of the metallodrug RAPTA-T on human cancer cells. Metallomics 2012; 4: 1185-96. doi: 10.1039/ c2mt20070h

71. Palermo G, Magistrato A, Riedel T, von Erlach T, Davey CA, Dyson PJ, et al. Fighting cancer with transition metal complexes: from naked DNA to protein and chromatin targeting strategies. Chem Med Chem 2016; 11: 1199-210. doi: $10.1002 / \mathrm{cmdc} .201500478$

72. Zou T, Lum CT, Lok CN, Zhang JJ, Che CM. Chemical biology of anticancer gold(III) and gold(I) complexes. Chem Soc Rev 2015; 44: 8786-801. doi: $10.1039 / \mathrm{c} 5 \mathrm{cs} 00132 \mathrm{c}$

73. Molter A, Kathrein S, Kircher B, Mohr F. Anti-tumour active gold(I), palladium(II) and ruthenium(II) complexes with thio- and selenoureato ligands: a comparative study. Dalton Trans 2018; 47: 5055. doi: 10.1039/ C7DT04180B

74. Tshuva EY, Miller M. Coordination complexes of titanium(IV) for anticancer therapy. Met lons Life Sci 2018; 18. doi: 10.1515/9783110470734-014

75. Cini M, Bradshaw TD, Woodward S. Using titanium complexes to defeat cancer: the view from the shoulders of titans. Chem Soc Rev 2017; 4: 104051. doi: $10.1039 / \mathrm{c} 6 \mathrm{cs} 00860 \mathrm{~g}$

76. Meléndez E. Titanium complexes in cancer treatment. Crit Rev Oncol Hematol 2002; 42: 309-15. doi: 10.1016/S1040-8428(01)00224-4

77. Ang DL, Gordon CP, Aldrich-Wright JR. Transition metal intercalators as anticancer agents - recent advances. Int J Mol Sci 2016; 17: 1-17. doi: 10.3390/ ijms17111818 